\title{
INEQUALITIES FOR THE DERIVATIVES
}

\author{
A. G. RAMM
}

Abstract. The following question is studied and answered:

Is it possible to stably approximate $f^{\prime}$ if one knows:

and

1) $f_{\delta} \in L^{\infty}(\mathbf{R})$ such that $\left\|f-f_{\delta}\right\|<\delta$,

2) $f \in C^{\infty}(\mathbf{R}),\|f\|+\left\|f^{\prime}\right\| \leqslant c$ ?

Here $\|f\|:=\sup _{x \in \mathbf{R}}|f(x)|$ and $c>0$ is a given constant. By a stable approximation one means $\left\|L_{\delta} f_{\delta}-f^{\prime}\right\| \leqslant \eta(\delta) \rightarrow 0$ as $\delta \rightarrow 0$. By $L_{\delta} f_{\delta}$ one denotes an estimate of $f^{\prime}$. The basic result of this paper is the inequality for $\left\|L_{\delta} f_{\delta}-f^{\prime}\right\|$, a proof of the impossibility to approximate stably $f^{\prime}$ given the above data 1 ) and 2), and a derivation of the inequality $\eta(\delta) \leqslant c \delta^{\frac{a}{1+a}}$ if 2$)$ is replaced by $\|f\|_{1+a} \leqslant m_{1+a}, 0<a \leqslant 1$. An explicit formula for the estimate $L_{\delta} f_{\delta}$ is given.

Mathematics subject classification (1991): 65D25, 65M10.

Key words and phrases: stable numerical differentiation, inequalities for the derivatives.

\section{REFERENCES}

[1] G. Hardy, J. Littlewood, G. Polya, Inequalities, Cambridge Univ. Press, London, 1951.

[2] A. Kolmogorov, On inequalities between derivatives, Uchen. Zapiski Moscow Univ. Math., 30, (1939), 3-16.

[3] E. LANDAU, Einige Ungleichungen für zweimal differentierbare Functionen, Proc. Lond. Math. Soc., 2, N13, (1913), 43-49.

[4] T. Miller, A. G. RAMm, Estimates of the derivatives of random functions II., J. Math. Anal. Appl., 110, (1985), 429-435.

[5] A. G. Ramm, Random fields estimation theory, Longman Scientific and Wiley, New York, 1990.

[6] _ On numerical differentiation, Izvestija vuzov, Mathem., 11, (1968), 131-135.

[7] _ Stable solutions of some ill-posed problems, Math. Meth. in appl. Sci., 3, (1981), 336-363.

[8] Estimates of the derivatives of random functions, J. Math. Anal. Appl., 102, (1984), 244-250.

[9] - On simultaneous approximation of a function and its derivative by interpolation polynomials, Bull. Lond. Math. Soc., 9, (1977), 283-288.

[10] Simplified optimal differentiators, Radiotech.i Electron., 17, (1972), 1325-1328.

[11] A. G. RAMm, A. B. SMIRnova, On stable numerical differentiation, (to appear). 